\title{
Orlanda Amarílis,
}

literatura de migrante

B enjamin Abdala J unior*

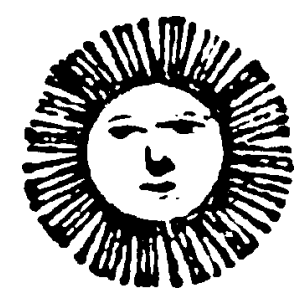

* Universidade de São Paulo. 
Num texto de 1989, analisamos a circulação cultural entre o B rasil, Portugal e África, tendo como motivo condutor a imagem de Pasárgada, de Manuel Bandeira. Procuramos então discutir essa figuração utópica por recorrência a Osvaldo Alcântara (pseudônimo poético de Baltasar Lopes) e a Ovídio Martins. O primeiro, com os "pés" em Cabo Verde, sonha à Bandeira com uma pasárgada que existiria em outra margem do oceano. Se o poeta brasileiro imagina um reino com um rei bonachão que lhe permitiria todas as "libertinagens" (título da coletânea do poeta brasileiro), Osvaldo Alcântara tem saudade de uma pasárgada futura que encontraria no "caminho de Viseu" ( ...indo eu, indo eu,/a caminho de Viseu" Osvaldo Alcântara, repetimos, estava com os pés em Cabo Verde, mas a cabeça inclina-se para fora, para as possibilidades de se encontrar plenitude na imigração. Sua perspectiva é aquela que historicamente sempre se colocou para seu povo de migrantes e ele não deixa de ter consciência de que esta saudade fi na de Pasárga da/é um veneno gostoso dentro do meu coração ${ }^{2}$. A partir das carências de sua terra, Osvaldo Alcântara sonha com o que não tinha.

A o contrário de O svaldo Alcântara, O vídio M artins - identificado com os pressupostos ideológicos da Casa dos Estudantes do Império em Lisboa - já estava insatisfeito com o reino de Pasárgada. Em oposição ao que ocorrera no sonho de Bandeira, ele não só não era amigo do rei (Vou-me embora pra Pasárgada/Lá sou amigo do rei/Lá tenho a mulher que eu quero/Na cama que escolherei - Apud: Idem. I bidem. p. 142) como foi perseguido por sua polícia. Não conseguindo per-

A pud B enjamin Abdala J unior, Literatura, hi stória e política, São Paulo, Ática, 1988, p. 49.

Idem. Ibidem, p. 49. 
manecer em Lisboa, foi obrigado a imigrar para a Holanda. O vídio Martins, como Osvaldo Alcântara, sonha com o que não tinha: justamente sua terra, Cabo Verde. Se Osvaldo Alcântara olha para horizontes indefinidos do mar, Ovídio Martins adota a perspectiva inversa: procura arremessar-se ao chão (Pedirei/Suplicarei/ Chorarei/Não vou para Pasárgada/Atirar-me-ei ao chão/e prenderei nas mãos convulsas/ervas e pedras de sangue/Não vou para Pasárgada³).

É dentro desse contexto que iniciamos nossas observações sobre os contos de Orlanda A marílis, uma obra também construída fora de seu país. M otivam-nos sobretudo colocações capazes de situá-la dentro do campo de nossos estudos - os Estudos Comparados de Literaturas de Língua Portuguesa. Parece-nos importante, neste momento de uma nova etapa do processo de mundialização da economia capitalista e vertiginosa estandardização de produtos, relevar nossa maneira de ser, adotando perspectivas de ordem comunitária (comunitarismo lingüístico e cultural). Voltando ao contexto criado a partir de $M$ anuel Bandeira, podemos afirmar que o olhar de Orlanda A marílis vai igualmente na direção inversa à do poeta brasileiro. Mais: ela não aceita a perspectiva patriarcal das libertinagens de $B$ and eira ${ }^{4}$, que reduziam o amor a atos sexuais com prostitutas; sua bandeira é outra, de caráter feminista.

Servirá de motivo condutor de nosso discurso o conto "Cais do Sodré", que pertence à coletânea Cais-do-Sodré té Salamansa, publicada um pouco antes dos Cravos de Abril ${ }^{5}$. E sse conto serve de pórtico para essa coletânea e permite identificar estratégias narrativas e motivos temáticos que têm recorrência no conjunto das produções de Orlanda Amarílis. Como se sabe, após a edição dessa coletânea, Orlanda Amarílis publicou ainda os seguintes de volumes de contos: Ilhéu dos Pássaros (1983) e A Casa dos Mastros (1989).

Começamos com duas citações que nos servem de primeiro contexto crítico. O primeiro é o ensaio "As M ulheres-Sós de Orlanda Amarílis", de M aria A parecida Santilli, que integra o livro Africanidade. ${ }^{8}$ R elevamos suas observações sobre a óptica feminista da escritora em Ilhéu dos Pássaros - perspectiva que a crítica brasileira associa também à coletânea anterior (Cais-do-Sodré té Salamansa). Citamos as conclusões de Maria Aparecida Santilli:

“N este último livro de contos, confirma-se o processo de elaboração da coleção anterior da E scritora, Cais-do-Sodré té Salamansa, fundamentalmente organizada sobre os sul-

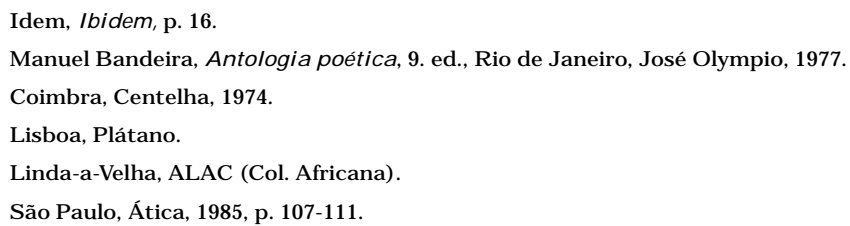


cos da memória, por convergência de pequeninas e múltiplas vertentes das recordações, canalizadas na rede de vasos comunicantes da intriga de ficção. A memória funciona, então, como sistema de estímulos para se irem abrindo as comportas da interligação de muitas caixinhas de segredo, revelando a pouco e pouco o retrato caprichoso de suas mal-amadas heroínas. Nas voltas delicadas para fundir o que "era" no que "é" caboverdiano fica delineada a solução literária "feminina" da Contista, quase como contraponto do estilo convulso, de "serpentinata" da memória de seu companheiro de letras caboverdianas, o M anuel Ferreira de Voz de Prisão.

A linguagem de Orlanda é ainda a das mulheres contidas, a caminho de libertarem-se do código de manifestação que a sociedade masculina ao longo dos tempos Ihes impôs."

Para Maria Aparecida Santilli, as mulheres-sós de Orlanda Amarílis - que têm no crioulo a sua forma lingüística de identificação - são personagens da literatura feminina universal. P retendemos retomar mais adiante esse sentido das articulações do discurso de Orlanda Amarílis.

Neste rastreamento crítico inicial, é de se apontar, em seguida, o estudo "Mulheres, Ilhas Desafortunadas", de Pires Laranjeira, que serve de prefácio ao livro A Casa dos Mastros, de Orlanda Amarílis. Para nossos objetivos, fazemos referência ao seguinte comentário:

"Passagem para a diáspora, a grande cidade [é o local] onde se instala a sôdade onde se tecem teias da cumplicidade (desde "Cais-do-Sodré", o primeiro conto do primeiro livro, sobre um encontro, sobre a Mãe Terra) [...] Com a diáspora por cenário se abrem os três livros de contos de Orlanda Amarílis, que logo se continuam em histórias localizadas no chão das ilhas, de outros tempos ( $\operatorname{anos} 30,40$ e 50, podemos adivinhar, quando não datadas [...]). Como que a dizer: o narrador-mor, pai de sete narradores, em cada conjunto de histórias, vive na diáspora, vivendo de recordações. O narrador recorda como (quem) fala, coloquiando, oralizante, fragmentário nas falas (discurso sincopado, em português, com o crioulo espreitando na língua literária), fragmentando as histórias em episódios soltos, ou quase $[\ldots] " 10$.

Como vimos, Maria A parecida Santilli, ao analisar o registro feminino da solidão das mulheres-sós em Orlanda A marílis, localiza-o não apenas em Il héu dos Pássaros: o processo seria anterior, observável na sua primeira coletânea de contos, sobretudo em "Cais-do-Sodré". Pires Laranjeira, na referência atrás e no conjunto desse seu prefácio, enfatiza a recorrência dos temas e procedimentos discursivos,

$9 \quad$ Idem, Ibidem, p. 111.

$10 \quad$ Idem, I bidem, p. 10. 
extensíveis ao conjunto da obra da contista. É de se destacar a ênfase dada ao local de onde fala o sujeito do discurso: Lisboa, um dos núcleos centrais da migração caboverdiana. A fala das mulheres-sós é de quem imigrou e diríamos, a partir de Pires Laranjeira, que o caráter sincopado dessa fala vem de uma situação de divisão: uma divisão no espaço (poderíamos dizer, como no título da primeira coletânea, entre "Cais-do-Sodré", local de onde parte a linha de Cascais - um dos suburbanos de L isboa, e a praia de Salamansa, em Cabo Verde); divisão também no tempo (em que a mesmice do presente da pretensa Pasárgada opõe-se a uma singularidade - mesmo que dramática e trágica - recuperada pela memória).

Dito de outra forma, o texto de ficção de Orlanda Amarílis mostra-se bastante auto-recorrente, criando um continuum como se a escritora estivesse sempre escrevendo um mesmo livro, com seus narradores trazendo novas visões dos mesmos objetos ou acréscimos de histórias intercaladas. Além disso, esse continuum do espaço-tempo, em oposição ao insulamento das mulheres-sós, cria ao nível da enunciação um espaço de solidariedade. Esse recorte é manifestação do desejo da escritora, de sua vontade. Ou, se quisermos, uma configuração virtual que cria horizontes capazes de levar o escritor e seus atores a dialogarem em termos de presente com seus leitores. Dessa forma, o que poderia ser denúncia da situação da mulher caboverdiana acaba também por constituir uma forma solidária de encontro. O texto, assim, não deixa de ser manifestação utópica: uma manifestação da vontade da escritora que acredita que as coisas possam ser diferentes do que são e se seu leitor, como boa parte de suas personagens, não pode modificar o mundo, poderá pelo menos modificar suas atitudes diante dele.

Voltemos ao conto "Cais-do-Sodré". É aí que se encontra uma das narradoras de Orlanda Amarílis, Andresa. Sua voz, repetimos, é exercida a partir de carências, não apenas aquelas recuperadas do referente Cabo Verde, mas sobretudo aquelas de quem se vê longe da terra e se encontra num "reino" frustrante. Esse reino, de características burguesas, move-se através de formas rituais tão estandardizadas quanto os seus produtos. Não se trata da outra civilização dos sonhos de M anuel B andeira. É um espaço que enreda as personagens de Orlanda Amarílis, levando-as a um mundo competitivo que seria o avesso daquele sonhado pelas perspectivas libertárias que balizam o horizonte estético-ideológico da contista. R elações de solidariedade entre essas personagens, quando ocorrem, são fugazes e podem ser creditadas a manifestações de ordem comunitária que invariavelmente apontam para os signos da identidade caboverdiana.

Entre esses signos, é central a língua literária de Orlanda Amarílis, um português padrão entrecruzado pela cadência oral do crioulo, ou língua caboverdiana. São dois níveis culturais que se disputam: o da literatura, modelada por uma tradição européia milenar (secular, se fizermos um recorte ligado à formação dos 
estados nacionais); e o da literatura oral (ou oralitura), em que o contributo das culturas africanas é essencial. Interessante a se assinalar é que Andresa, a personagem central do conto, que se encontra na estação de Cais-do-Sodré em L isboa, vê-se enredada de tal maneira pela língua de identidade nacional, que parece ter simbolicamente seus passos orientados por sua lógica discursiva. Numa das imagens centrais dessa narrativa, extensiva ao conjunto das produções de Orlanda Amarílis, essa personagem parece modelada pela língua, tornando-se uma atriz que expressa a sua maneira de ser enquanto produto originário de duas culturas.

E m oposição à estandardização, estamos procurando relevar marcas deidentidade (individual e nacional). A identidade nacional, em Orlanda Amarílis, está nas marcas da di ferença caboverdiana. Essa diferença, mediada pela sua linguagem artística, aponta para os signos comunitários compartilhados pela nação caboverdiana, entendida no sentido antropológico desenvolvido por Benedict Anderson em Nação e Consciência Nacional ${ }^{11}$ : a nação como comunidade política imaginada, em que se desconsidera a desigualdade e a exploração, isto é, as diferenças internas, em favor de um companheirismo profundo e horizontal. É uma espécie de extensão dos laços de parentesco, tendo como base um sentimento de fraternidade, sem que as pessoas se conheçam.

Mas Andresa está na estação de Cais-do-Sodré, ponto de partida e de chegada da linha de suburbano que segue paralelamente à foz do Tejo, trajetória análoga às das antigas embarcações que se dirigiam ao Atlântico. E, por trás dessa personagem, está Orlanda A marílis. O sentido do deslocamento do trem/comboio é aquele que levaria até a praia de Salamansa? O título da coletânea de contos é Cais-do-Sodré té Salamansa: o té é da oralidade crioula e Salamansa é uma praia caboverdiana. Ou o suburbano levaria à região periférica de Lisboa, onde o caboverdiano é sinônimo de proletário? Tais ambigüidades, na verdade, valorizam a narrativa de Orlanda A marílis quando são estabelecidos laços comunitários supranacionais ao lado de diferenças. A caracterização da maneira de ser caboverdiana constitui matizações equivalentes àquelas que separam regiões ou a cidade do campo.

A Ilha de São Vicente, onde se localiza a cidade de Mindelo, é a referência básica de Orlanda A marílis. Na ambiência insular de uma cidade média, a atividade social se circunscreve e todos se conhecem. E, ao curso das conversas, configuram-se os elos de articulação da comunidade:

“Oh gente, se encontra pessoas, como ela, vindas daquelas terras de espreguiçamento e lazeira, associa-as quase sempre a uma ou outra família. Se não as conhece, bom, de certe-

11 São Paulo, Ática, 1989. 
za conheceu o pai ou o primo ou o irmão, ou ainda uma tia velha, doceira de fama, até talvez uma das criadas lá da casa. E a conversa, por esse elo, estende-se, alarga-se, num desfolhar calmo, arrastado, saboroso quase sempre."12

A linguagem não exclui, mas inclui, constituindo forma de integração social. Seu ritmo traz as marcas do "desfolhar calmo" da vida caboverdiana, diferentemente do que acontece na antiga metrópole. Poder-se-ia talvez afirmar que há na cultura popular de Cabo Verde (ou mesmo do Brasil) um Portugal que já não existe na capital metropolitana. Como o Brasil, Cabo Verde também possui uma cultura crioula - isto é, uma cultura formada de pedaços da cultura portuguesa e de várias culturas africanas, formando um todo mestiço não-unívoco, não-sintético, ao contrário do que acontece com povos de formação mais antiga.

Orlanda Amarílis está assim na encruzilhada entre Portugal e Cabo Verde. Suas narrativas, como "Cais-do-Sodré", pautam-se pela ênfase social na definição da identidade cultural. Em Cabo Verde, essa forma de consciência evolui de uma perspectiva regional (as produções, sobretudo as primeiras, da revista Claridade) para uma consciência nacional. Ou, como se apontava na crítica neo-realista, o nacional deveria fincar pé na região. Essa estratégia de identificação era avessa ao cosmopolitismo desfigurador. Por extensão, os leitores de Orlanda Amarílis têm em seus contos produtos contrapostos à estandardização da indústria cultural, que hoje, dentro da globalização neo-liberal, leva os mesmos produtos para todos os pontos do planeta. A estandardização vem de uma nova forma de imperalismo ligada ao enfraquecimento do Estado, substituído pela força da corporação multinacional. Se um dos tópicos do Neo-R ealismo foi analisar a decadência diante das novas técnicas de produção, agora esse processo que se confinava mais à região de um país torna-se supranacional.

A busca da diferença não deixa, pois, de ser uma forma de defesa. Entretanto, isso não pode significar a simples volta às formas de produção anteriores, já que o conhecimento técnico também é um patrimônio coletivo. Em “Cais-doSodré", a narradora mostra notável conhecimento das implicações sociolingüísticas de sua linguagem artística. Não se reduz a uma perspectiva mimética na incorporação do crioulo: uma identidade, poder-se-ia entender, voltada para trás, de costas para o futuro, por onde se afirmam características folclóricas. Sua linguagem imbrica, como dissemos, o português padrão com o crioulo, ou língua caboverdiana, com grande produtividade lingüística. E mbora Orlanda Amarílis procure recuperar o passado pela memória, seu olhar volta-se para o devir, tornando possíveis estratégias textuais que não se deixam seduzir por um passadismo folclórico, afim

12 Cais-do-Sodré té Salamansa. p. 9. 
das ópticas neocoloniais. Constitui, ao mesmo tempo, é necessário que se ressalte, um produto cultural que tem possibilidades de colocação num mercado mais restrito. Sob esse aspecto de consciência do caráter da circulação, em que as mídias são essenciais, as produções empenhadas contemporâneas afastam-se daquelas das décadas de 30-50.

Voltando ao início do conto, podemos visualizar a personagem Andresa na estação de Cais-do-Sodré. Sua primeira reação, ao se encontrar com sua compatriota Tanha, foi se afastar. Entretanto, os funções sociais da linguagem, imbricadas na fala de Andresa, acabaram por determinar uma lógica discursiva mais forte que suas motivações conscientes. A interlocução, como forma de sociabilidade, acabou por enredar na própria fala da personagem os signos de identidade (individual e nacional). A estratégia discursiva da conversa é de domínio geral: perguntas para se levantar laços de parentesco, uma familiaridade ou fraternidade. A terra-mãe torna-se assim, desde uma distância metropolitana, uma imagem utópica de vida comunitária, contraposta às relações cotidianas da grande cidade. Conversa vai, conversa vem, Andresa acaba por descobrir a origem da interlocutora: ela era filha de Simão Filili. Essa personagem marcou parte do imaginário de Andresa, quando ela ainda era criança. Simão Filili, pelas margens da sociedade de $\mathrm{M}$ indelo, foi personagem de impacto por afrontar comportamentos tradicionais. É de se citar Orlanda A marílis, no momento em que Andresa faz essa descoberta:

"Agora sim, Andresa conseguiu mais ou menos os cordéis e sente-se à vontade. Quem poderia esquecer o homem pequenino e chupado daquela casa vermelha ali no Alto de Celarine? Só quem nunca tivesse ouvido contar histórias de gongon, histórias de correntes arrastadas na estrada da Pontinha, em noites de ventania, por artes do xuxo, ou das trupidas dos cavalos a atravessarem a morada por volta da madrugada. O povo só se Ihes referia ao barulho fragoroso das patas raspando o empedrado. Andavam a pregar a tumba de nhô Vendido dizia-se. Nha Xenxa, viúva de nhô J oão Sena, contava, e a voz velava-se-lhe de medo (...)"13

A procura da identidade, através da chamada "literatura oral" (ou, se se quiser, oralitura), leva o narrador a incorporar formas do imaginário popular. E m alguns momentos da obra de Orlanda Amarílis, o discurso do narrador não se distancia dos relatos das personagens, impregnando-se de referências fantásticas. Assim a identidade faz-se por dentro e não apenas através do discurso referido. $E$ 
a estratégia discursiva, ao nível da efabulação, torna-se simétrica com o já indicado ao nível lingüístico.

Nessa situação narrativa que incorpora o "causo" de Simão F ilili - uma história encaixada dentro do conto - é notória a religiosidade cristã da ideologia oficial, que não aceita a diferença do outro: um maçom, relegado à solidão. N esses relatos originários da oralitura, o fantástico vem de fontes culturais crioulas, na mescla do misticismo das culturas africanas com o dos primitivos colonos portugueses que vieram ter ao arquipélago. Simão Filili, no passado, despertou medo na menina Andresa; agora, no presente da enunciação, sua figura é recuperada com empatia.

Os "causos" de Orlanda A marílis são relatados, conforme indicamos, sobretudo por vozes femininas. À identidade da nação soma-se a do assim chamado "gênero". Não se trata apenas de representar Cabo Verde, mas de construir a "maneira de ser" das mulheres caboverdianas. Intensificam-se, então, as marcas de diferenças da "comunidade imaginada", mas parece-nos que são atenuadas aquelas desse caráter comunitário supranacional. Essa foi uma outra perspectiva do Neo-R ealismo: construir um texto que viesse de uma situação concreta (econômica e social), própria de uma nação, mas que tivesse sua universalidade pela ação de fatores comunitários. Veio dessa preocupação um notável diálogo entre os artistas (literatura, cinema, artes plásticas e visuais) que participaram de forma direta ou indireta da frente popular antifascista, do período entre-guerras, e que se projetou nos primeiros anos da guerra-fria.

A perspectiva supranacional pressupunha a diferença do assim chamado "típico" de cada país ou condição social. E o típico, ao contrário dos que o confinam ao estereótipo, implicou a representação ambígüa, problemática, como pode ser observado na construção da personagem Andresa, de "Cais-do-Sodré". Aí a predicação individual, singular, da personagem central da narrativa interage - sem se reduzir - com os atributos de ordem social. Ou, conforme se dizia dentro da óptica do realismo crítico, ela se coloca como uma heroína problemática diante do mundo alienado.

Dessa forma, Orlanda Amarílis procura aquilo que lhe falta e também a suas personagens. Não obstante as carências que poderiam levá-las a um emparedamento trágico ao gosto neo-naturalista, sempre acaba restando alguma luz no horizonte. Observado de Lisboa, o insulamento da terra não deixa de ser um elemento mítico de encontro. Uma utopia registrada criticamente e que propicia o nascimento de projetos. Não um sonho abstrato, devaneio, mas um sonho diurno de quem tem conviç̧ões transformadoras. Este é um outro traço de Orlanda A marílis: num mundo apático, de indiferença social, ela tem convicções. 
Orlanda Amarílis incorpora o "papiâ" caboverdiano. As conversas costuram as narrativas, que se iniciam no Cais-do-Sodré e se dirigem aos subúrbios, uma linha vetorial que chega a Cabo Verde. A imagem da costura ou tecedura é aqui adequada para explicar o processo de composição de Orlanda A marílis - uma produção artesanal, restrita aos papeares domésticos. Suas narradoras são sucedâneas, na escrita, dos antigos "griots" africanos. Uma dessas vozes narrativas em "Cais-do-Sodré" é Bia Antónia:

"Bia Antónia, a velha criada da casa, era quem contava estas e outras patranhas à Andresa. Depois do jantar, Bia Antónia sentava-se num caixote, perto da escada, na varanda sobranceira ao quintal. Entre duas fumaças do canhoto sempre dependurado no canto da boca, a serva desfiava um ror de histórias."14

A imagem de Bia Antónia com o fumo no canto da boca, é correlata à dos "griots" suburbanos do continente africano. Há, pois, comutação de papéis, como também veio a ocorrer no continente. Símbolo de identidade, essas contadoras de história preservam a memória da terra - sempre uma terra-mãe. Essa simbolização feminina leva-nos a situá-la como uma Mátria (no dizer de uma feminista, Natália Correia), em oposição à Pátria (de caráter patriarcal, masculina), identificada com o poder colonial. É interessante indicar que boa parte dos escritores do chamado Neo-R ealismo (no Brasil e na África) tiveram em sua infância uma contadora de histórias, normalmente de origem negro-africana, no caso brasileiro.

O enredamento de Andresa, na própria dinâmica da conversa deve-se a uma atração avassaladora que a leva a procurar os símbolos de sua identidade, ocorre independentemente de sua vontade. Ela queria preservar a distância social que a separava de seus compatriotas, mas não consegue: a função social da linguagem de que se vale imprime toda uma lógica discursiva que acaba por escapar de suas intenções iniciais. Essa lógica vem de seu inconsciente e determina o processo, revelando seu ser interior que não se conforma com os estereótipos de sua conduta social em Lisboa. Seu papel é outro. A pós a interlocução com Tanha, Andresa procura subterfúgios para se afastar da compatriota, embora fosse na mesma direção. Quando Tanha se afasta para tomar o trem, ela continua na estação. Vê-se, então, num banco ao lado de uma inglesa ruiva e percebe que pouco tinha a ver com ela. Não teve dúvidas em ir atrás de Tanha, para continuar suas conversas.

A identidade feminina, como se vê, caminha ao lado da identidade nacional. E ra a perspectiva do N eo-R ealismo. Mais: essa perspectiva associa reivindicações

$14 \quad$ Idem, Ibidem, p. 17. 
de gênero às sociais. I sto é, as articulações feministas subordinavam-se às sociais, da mesma forma que as de natureza étnica, tão presentes no contexto africano. Neste momento de globalização, a tendência dominante é a articulação comunitária, que envolveriam as mulheres independentemente de suas condições sociais. Há fragmentação, mas a articulação torna-se mais enfática e específica, em face do enfraquecimento dos estados nacionais. Se se afirma de forma dominante a lógica da corporação, o feminismo não deixa de ser uma resposta a ela. Entretanto, em Orlanda A marílis continua a visão totalizadora do Neo-R ealismo, com suas vinculações político-sociais ligadas diretamente à esfera do trabalho. O feminismo articulado, assim, a reivindicações mais gerais, de ordem social. Andresa, assim, não se vê identificada com a inglesa ruiva, que - apesar de mulher - era diferente dela do ponto de vista étnico e lingüístico.

A identidade individual e nacional prende-se, assim, à cultura. $\mathrm{N}$ ão à cultura em geral, mas de como esta é apropriada às margens do sistema - outro tópico Neo-R ealista. Trata-se de uma apropriação feminista e de caráter popular. $O$ trabalho artístico de Orlanda A marílis pauta-se justamente por essas formas de produtividade. $O$ diferente vem do fato de que as marcas feministas é que se articulam ao social e não o contrário, como acontecia nas obras de autoria masculina. A condição social agrava uma distonia anterior, que seria de gênero. Tudo, é claro, dentro dos horizontes da nação e das questões político-sociais por ela delimitadas. Observe-se o seguinte "causo" em torno de Zinha, irmã de Tonha:

"Zinha andava doente há longos meses de uma doença esquisita. A pele virara-se baça e de cor suja. O noivo lá para G uiné e o povo murmurava. Doença assim não podia ter outra origem senão mal-feitiço feita pela amante preta de Bissau. Vocês não sabiam? Gente da Guiné fazia mal-feitiço por tudo e por nada. Também não era novidade: Qualquer rapaz solteiro costumava arranjar a sua rapariga e, muitas vezes, um ou dois filhos antes de casar com outra. Q uanto à Zinha, mal-feitiço ou não, a verdade era ela estar doente. M al-feitiço ou não, muita gente nova de Soncente morria tuberculosa e, se crianças ainda, morriam de febre tifóide, e se meninos de mama, morriam com desinteria. Então, pâ mode quê tanta tolice de boca para fora?"15

As referências de ordem social contextualizam as de gênero, embora o ponto de observação situe-se na mulher. N esses momentos, narradoras burguesas, como Andresa, abandonam pontos de vista de classe, aderindo à óptica de quem observa o sistema não propriamente com os "pés", mas sobretudo com a "cabeça" em Cabo Verde, como pretendia uma das personagens do caboverdiano Manuel Lopes 
(Galo Cantou na Baía e Outros Contos ${ }^{16}$.). É a narradora de "Cais-do-Sodré" que informa o leitor sobre essa identificação:

"Andresa relembra tudo isso com tanta minúcia como se tivessem passado dias atrás. Como se nunca se tivesse despegado da M ãe-Terra, e tivesse continuado as pegadas de nhô Simão Filili, de nhô Faia, de Antoninho Ligório, do Pitra."17

A adesão empática vem, pois, dentro das condições da migração. Como se sabe, há mais caboverdianos fora do que dentro de seu país. E articulações de caráter comunitário, como a das narradoras de Orlanda Amarilis, podem ser manifestações das potencialidades de articulações supranacionais onde se preservem as diferenças. O caminho suburbano aponta a direção. Para quem observa em sua perspectiva, é possível visualizar alguma luz no horizonte.

Para finalizar, parece-nos importante relevar alguns pontos indicados nesse nosso percurso:

1. As formulações utópicas que envolveram a formação da literatura caboverdiana, com um horizonte voltado entre o partir e o ficar, revestem-se hoje de atualidade, quando antigas fronteiras nacionais diminuem suas distâncias, mais parecendo novas formas de regionalismo. Orlanda A marílis situa-se criticamente num dos pólos dessa tensão, mas volta-se para suas origens, procurando uma adesão empática para um Cabo Verde dos anos 30-50.

2. Sua literatura é do migrante, com a enunciação revelando tensões da atualidade lisboeta e o enunciado trazendo situações do passado de Cabo Verde. Essa recuperação, pela memória, segue padrões da estética Neo-R ealista. Certas marcações enfáticas da exploração do homem pelo homem, ou da mulher pelo homem, que poderiam ser creditadas a uma espécie de neo-naturalismo à maneira, por exemplo, de Luís R omano, parece-nos mais afins do expressionismo. Podemos associar essas deformidades a um contexto mais amplo, dentro dos países de língua portuguesa, se parafrasearmos o são-tomense F rancisco J osé Tenreiro em "Coração em África":

“(...) de coração em África com as mãos e os pés trambolhos disformes/e deformados como os quadros de Portinari dos estivadores do mar/e dos meninos ranhosos viciados pelas olheiras fundas das gomas de Pomar/vou cogitando na pretidão do mundo que ultrapassa a própria cor da pele/dos homens brancos amarelos negros( ...)"18

\footnotetext{
3. ed., Lisboa, E dições 70, 1984.

Idem, Ibidem, p. 21.

A pud: Benjamin Abdala J unior, op. cit., p. 186
} 
3. Essa é a perspectiva de internacionalização do que se convencionou chamar em Portugal de Neo-realismo - uma corrente artística voltada para uma inserção crítica no real, e suas perspectivas de transformação. Ao contrário dos produtos estandardizados da mundialização procurou, como acontece em Orlanda Amarílis, a identidade de seus produtos culturais (identidades individuais, regionais ou nacionais). Discutir a dialética dessas identidades, neste momento, pode ser uma das formas de se opor à estandardização descaracterizadora. Se esta última etapa da mundialização (rotulada ideologicamente de globalização) vale-se do enfraquecimento dos Estados Nacionais para impor a lógica da corporação multinacional e seus produtos estandartizados, a internacionalização que apontamos mostra formas de associações comunitárias supranacionais. E, nós - brasileiros, portugueses e africanos - podemos começar relevando o comum de nossas diferenças.

4. A ficção de Orlanda Amarílis, com sua óptica feminina, é também uma forma de articulação supranacional. E ntretanto, sua perspectiva não se restringe aos horizontes mais cirscunscritos da chamada "literatura de gênero", porque tem o sentido da totalidade - uma totalidade imaginada, conforme a aspiração neorealista. Sua óptica, entretanto, não deixa de ser de "gênero": da maneira equivalente às produções paradigmáticas desse movimento estético-ideológico, que procura o geral através do particular, a nação através da região, o coletivo através do individual. em tensões que se pretende sejam problematizadoras, O rlanda A marílis vê seu povo de migrantes através da mulher - da adversidade de sua condição olha para uma adversidade mais geral.

5. J á se escreveu sobre os nosso tempo classificando-o como uma época de indiferença: uma pretensa democracia não como forma de respeito ao "outro", mas como ideologia da indiferença. A ficção de Orlanda Amarílis recoloca o homem no centro de suas preocupações. O "papiâ" que lhe serve de estratégia discursiva é uma forma de encontro, de aproximação. À perspectiva anômica da dispersão, solidão, individualismo, opõe a solidariedade, procurando, assim, analogicamente, a discursividade dos contadores de estórias. Assim, além de memória cultural de seu povo, sua ficção constitui produção simbólica solidária (enquanto tal, concretiza laços de solidariedade), pela intercalação de múltiplas vozes e múltiplos "causos". 
Referências bibliográficas:

ANDERSON, B enedict. Nação e consci ência nacional. São Paulo, Ática: 1989.

AMARÍLIS, Orlanda. Cais-doSodré té Salamansa. Coimbra: Centelha, 1974.

- Il héu dos pássaros. Lisboa: Plátano, 1983.

- A casa dos mastros. Linda-a-Velha: ALAC (COL. Africana), 1989.

ABDALA J UNIOR, B enjamin. Literatura, história e política. São Paulo: Ática, 1988.

BANDEIR A, M anuel. Antologia poética. 9. ed. Rio de J aneiro: J osé Olympio, 1977.

LOPES, Manuel. Galo cantou na baía e outros contos. 3. ed. Lisboa: Edições 70, 1984.

SANTILLI, Maria A parecida.Africanidade. São Paulo: Ática, 1985. 